\title{
Burnout Among Primary School Teachers in the Wazzane Region in Morocco: Prevalence and Risk Factors
}

Abdeslam Amri ${ }^{1}$, Zakaria Abidli ${ }^{2,}$, Mounir Bouzaaboul $^{1}$, Rabea Ziri ${ }^{1}$, Ahmed Omar Touhami Ahami ${ }^{1}$

${ }^{1}$ Cognitive Behavioral Neuroscience and Applied Nutrition Team, Faculty of Sciences, University of Ibn Tofail, Kenitra, 1400, Morocco

${ }^{2}$ Genetics and Biometrics Laboratory, Faculty of Sciences, University of Ibn Tofail, Kenitra, 1400, Morocco

\begin{tabular}{l} 
A R T I C L \\
\hline Article histor \\
Received: 09 \\
Accepted: 16 \\
Online: 24 Nove \\
\hline Keywords: \\
Burnout \\
Prevalence \\
Risk factors \\
Teachers \\
Primary \\
Morocco
\end{tabular}

\section{Introduction}

Burnout is a negative psychic experience experienced by an individual; it is related to chronic emotional stress caused by working to help people [1]. Maslach and Jackson [2] identified three characteristics of the burnout syndrome:

Emotional exhaustion: It refers to the feeling of being drained of one's emotional and physical resources and leads to difficulties in regarding to the emotions of the other. It represents the basic response to stress.

Depersonalization: It represents a negative or excessively detached response towards other people who are considered as objects.

Loss of personal accomplishment: It refers to feelings of incompetence and inefficiency, lack of success and productivity at work.

\footnotetext{
*Corresponding Author: Zakaria ABIDLI, zakaria.abidli@uit.ac.ma
}

Teachers are part of at-isk populations of workers who may be exposed to the burnout syndrome [3]. Indeed, Maslach and Travers have identified several socio-demographic and occupational risk factors for teacher burnout $[4,5]$. In our context, no study has been carried out among primary school teachers. For this reason, we aim to determine the prevalence and risk factors of burnout among a population of primary school teachers in the Wazzane district (Morocco).

\section{Methods}

This cross-sectional study lasted six months, from December 2017 to June 2018. It concerned teachers working in public primary schools in the region of Wazzane in North-West of Morocco. Socio-demographic and work-related data were evaluated by a self-administered questionnaire and by the 29-item Karasek Job Content Questionnaire (JCQ) [6], which measures three different scales: Work overload with 9 items: 10, 11, 12, 13, 14, 15, 16, 17 and 18. Decision latitude with 9 items, subdivided into two sub-scales : the use of skills or qualifications with 6 items: 
1, 2, 3, 4, 5, 6 and decision-making autonomy with 3 items: 7, 8, 9. Social support with 11 items, 6 items for support from colleagues : 19, 20,21, 22, 23, 24 and 5 items for hierarchical support: 25, 26, 27, 28, and 29. The Maslach Burnout Inventory MBI to 22 items that explore three scales has evaluated burnout [7]: Emotional exhaustion assessed by items $1,2,3,6,8,13,14,16,20$; Depersonalization assessed by items $5,10,11,15,22$; and loss of personal accomplishment assessed by items 4,7,9,12,17,18,19 and 21.These two questionnaires were validated and adapted to the context of Moroccan teachers.

For burnout, a score was calculated and a severity rating (low, moderate, and high) was assigned for each dimension. Emotional exhaustion was considered pathological for a score above 29, depersonalization for a score above 22, and personal accomplishment was considered low for a score below 11. The number of dimensions affected characterizes the degree of severity of burnout, so a single affected dimension determines low burnout, two affected dimensions determine moderate burnout, and three affected dimensions determine severe burnout (high emotional exhaustion and depersonalization scores, low personal accomplishment score). Statistical analysis was realized using SPSS version 21. Frequencies and percentages were calculated for the categorical variables, and the chi-square test $\left(X^{2}\right)$ was used to evaluate the differences between these variables. Continuous numerical data were summarized as mean and standard deviation. Logistic regression was used to determine the predictors of burnout; a p-value $<$ was considered statistically significant.

\section{Results}

For the 330 participants who completed the data sheet, the average age was $38.4 \pm 8.9$ years, with a minimum age of 24 and a maximum age of 59. The sex ratio was 1.7 in favor of males. The average years of service was $16.3 \pm 8.9$ years. $46.7 \%$ are between the ages of 35 and $49 ; 62.4 \%$ are male; $52.4 \%$ are married and $48.5 \%$ have years of service between 11 and 24 .

In terms of work-related characteristics, $40 \%$ managed multigrade classes; $61.5 \%$ had problems due to student demotivation; $54.5 \%$ had problems due to equipment didactic; $19.1 \%$ reported conflicts with colleagues; $12.4 \%$ with administration; workload was high for $57.5 \%$; decision-making autonomy was low for $42.7 \%$, and social support was low for $45.2 \%$ of participants (Table 1).

Table 1: Sociodemographic and work-related characteristics of primary school teachers $(\mathrm{n}=330)$ in Wazzane, 2017/2018.

\begin{tabular}{|l|l|l|}
\hline Variable & Number & Percentage \\
\hline Age & & \\
$24-34$ & 125 & $37.9 \%$ \\
$35-49$ & 154 & $46.7 \%$ \\
$\geq 50$ & 51 & $15.4 \%$ \\
\hline Sex & & \\
& & \\
Male & 206 & $62.4 \%$ \\
female & 124 & $37.6 \%$ \\
\hline Marital status & & \\
& & $52.4 \%$ \\
Married & 173 & \\
\hline
\end{tabular}

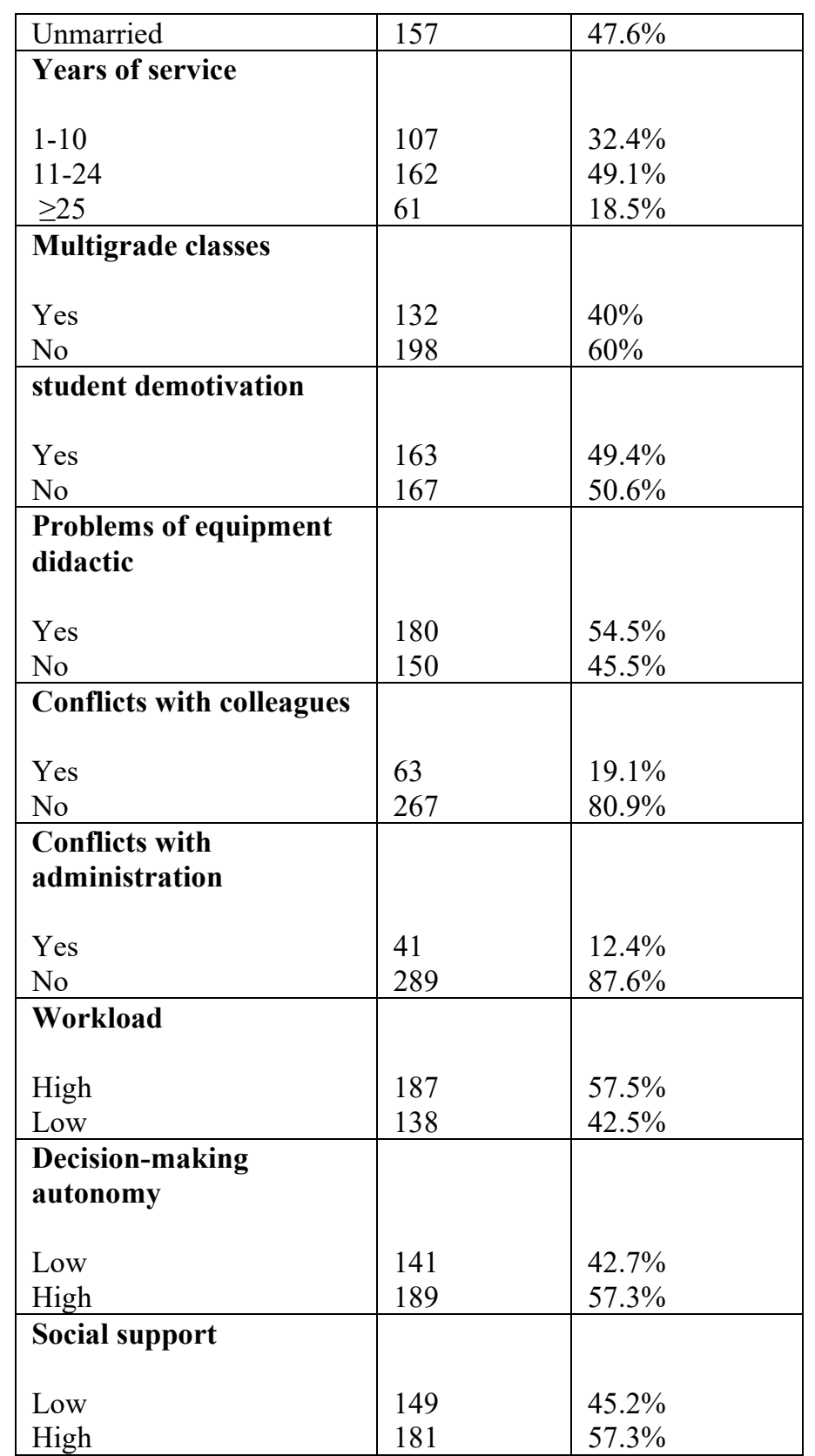

For the three dimensions of the burnout syndrome (emotional exhaustion, depersonalization and personal accomplishment), the average scores were respectively 21.8 $\pm 9.1 ; 14.1 \pm 9.9$ and 15.1 1 8.4.

Pathologically, emotional exhaustion was high for $23.9 \%$; depersonalization was high for $24.2 \%$ and personal accomplishment was low for $27.6 \%$ of participants (table 2).

Similarly, the Maslach Burnout Inventory revealed that 154 teachers $(46.6 \%)$ were victims of burnout, which $79(23.9 \%)$ had a low level; 47 (14.2\%) had a moderate level and $28(8.5 \%)$ had a severe burnout (Figure 1).

Regarding sociodemographic risk factors, the chi-square test showed that age and years of service were not significantly associated with burnout, while gender was found to be significantly associated with burnout $(\mathrm{p}<0.01)$. Marital status was also significantly associated with burnout: married were more burned out than unmarried $(\mathrm{p}<0.001)$ (Table 3$)$. 
Table 2: Means, standard deviations and prevalence of the three dimensions of Burnout among primary school teachers $(\mathrm{n}=330)$ in Wazzane, $2017 / 2018$.

\begin{tabular}{|l|l|l|l|l|}
\hline Variable & Mean & Standard- Deviation & Pathological cases & Prevalence \\
\hline Emotional exhaustion & 21.8 & 9.1 & 79 & $23.9 \%$ \\
\hline Depersonalization & 14.1 & 9.9 & 80 & $24.2 \%$ \\
\hline Personal accomplishment & 15.1 & 8.4 & 91 & $27.6 \%$ \\
\hline
\end{tabular}

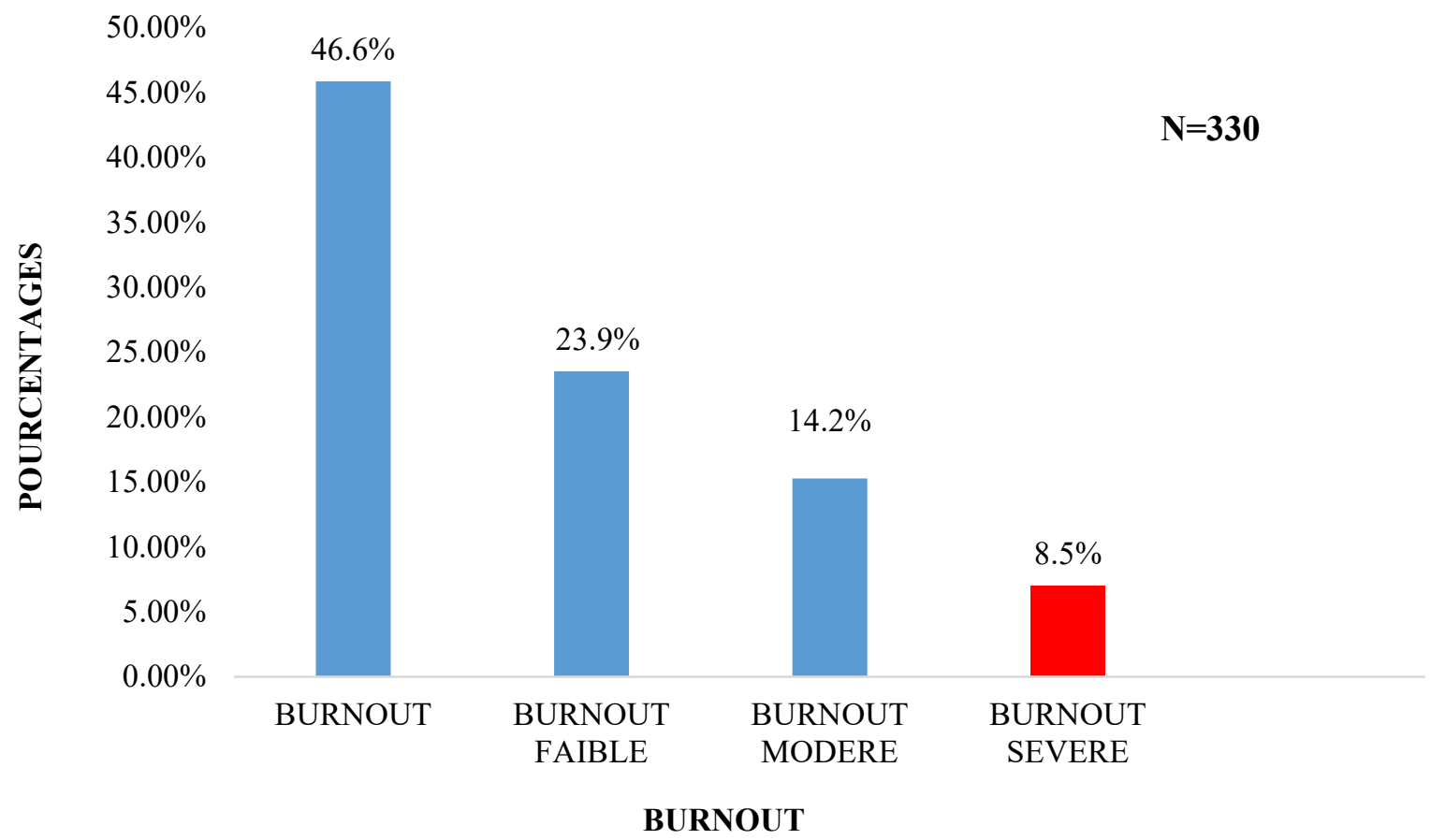

Figure 1: Profile of burnout syndrome among primary school teachers $(n=330)$ in Wazzane, 2017/2018.

Table 3: Association of burnout with sociodemographic risk factors among primary school teachers $(\mathrm{n}=330)$ in Wazzane, $2017 / 2018$.

\begin{tabular}{|c|c|c|c|c|c|c|}
\hline \multirow{2}{*}{$\begin{array}{l}\text { Variable } \\
\text { Age }\end{array}$} & \multicolumn{2}{|c|}{ Burnout } & \multicolumn{2}{|c|}{ No burnout } & \multirow[t]{2}{*}{ Chi-square } & \multirow[t]{2}{*}{ p-value } \\
\hline & Number & $\%$ & Nur & & & \\
\hline $\begin{array}{l}\text { Age } \\
24-34 \\
35-49 \\
\geq 50\end{array}$ & $\begin{array}{l}57 \\
75 \\
22\end{array}$ & $\begin{array}{l}37.0 \% \\
48.7 \% \\
14.3 \%\end{array}$ & $\begin{array}{l}68 \\
79 \\
29\end{array}$ & $\begin{array}{l}38.6 \% \\
44.9 \% \\
16.5 \%\end{array}$ & 0.56 & n .s \\
\hline $\begin{array}{l}\text { Sex } \\
\text { Male } \\
\text { female }\end{array}$ & $\begin{array}{l}78 \\
76 \\
\end{array}$ & $\begin{array}{l}50.6 \% \\
49.4 \% \\
\end{array}$ & $\begin{array}{l}128 \\
48 \\
\end{array}$ & $\begin{array}{l}72.7 \% \\
27.3 \% \\
\end{array}$ & 17.06 & $<0.001$ \\
\hline $\begin{array}{l}\text { Marital status } \\
\text { Married } \\
\text { Unmarried }\end{array}$ & $\begin{array}{l}101 \\
53 \\
\end{array}$ & $\begin{array}{l}65.6 \% \\
34.4 \% \\
\end{array}$ & $\begin{array}{l}72 \\
104 \\
\end{array}$ & $\begin{array}{l}40.9 \% \\
59.1 \% \\
\end{array}$ & 20.05 & $<0.001$ \\
\hline $\begin{array}{l}\text { Years of service } \\
1-10 \\
11-24 \\
\geq 25\end{array}$ & $\begin{array}{l}51 \\
73 \\
30\end{array}$ & $\begin{array}{l}33.1 \% \\
47.4 \% \\
19.5 \%\end{array}$ & $\begin{array}{l}56 \\
89 \\
31\end{array}$ & $\begin{array}{l}31.8 \% \\
50.6 \% \\
17.6 \%\end{array}$ & 0.36 & $\mathbf{n} \cdot \mathbf{s}$ \\
\hline
\end{tabular}


For work-related risk factors, the chi square test showed that burnout was significantly related to the management multigrade classes $(p<0.001)$, the student demotivation $(p<0.001)$, the problems of equipment didactic $(p<0.01)$, the conflicts with colleagues $(p<0.001)$, the conflicts with administration $(p<0.01)$, the work overload $(\mathrm{p}<0.01)$, the low decision-making autonomy $(\mathrm{p}<0.001)$ and the low social support $(\mathrm{p}<0.01)$ (Table 4$)$.

Logistic regression analysis showed that gender was the only sociodemographic variable that predicted burnout; while the workrelated variables that predicted it were:
Problems of equipment didactic, student demotivation, conflicts with colleagues, work overload and Low Decisionmaking autonomy (Table 5).

These results show the importance of knowing certain stress factors specific to the teaching profession. Thus, problems of didactic equipment, student demotivation, work overload and low decision-making autonomy are risk factors that threaten the psychological health of the Moroccan teacher.

Table 4: Association of burnout with work-related risk factors among primary school teachers $(n=330)$ in Wazzane, 2017/2018.

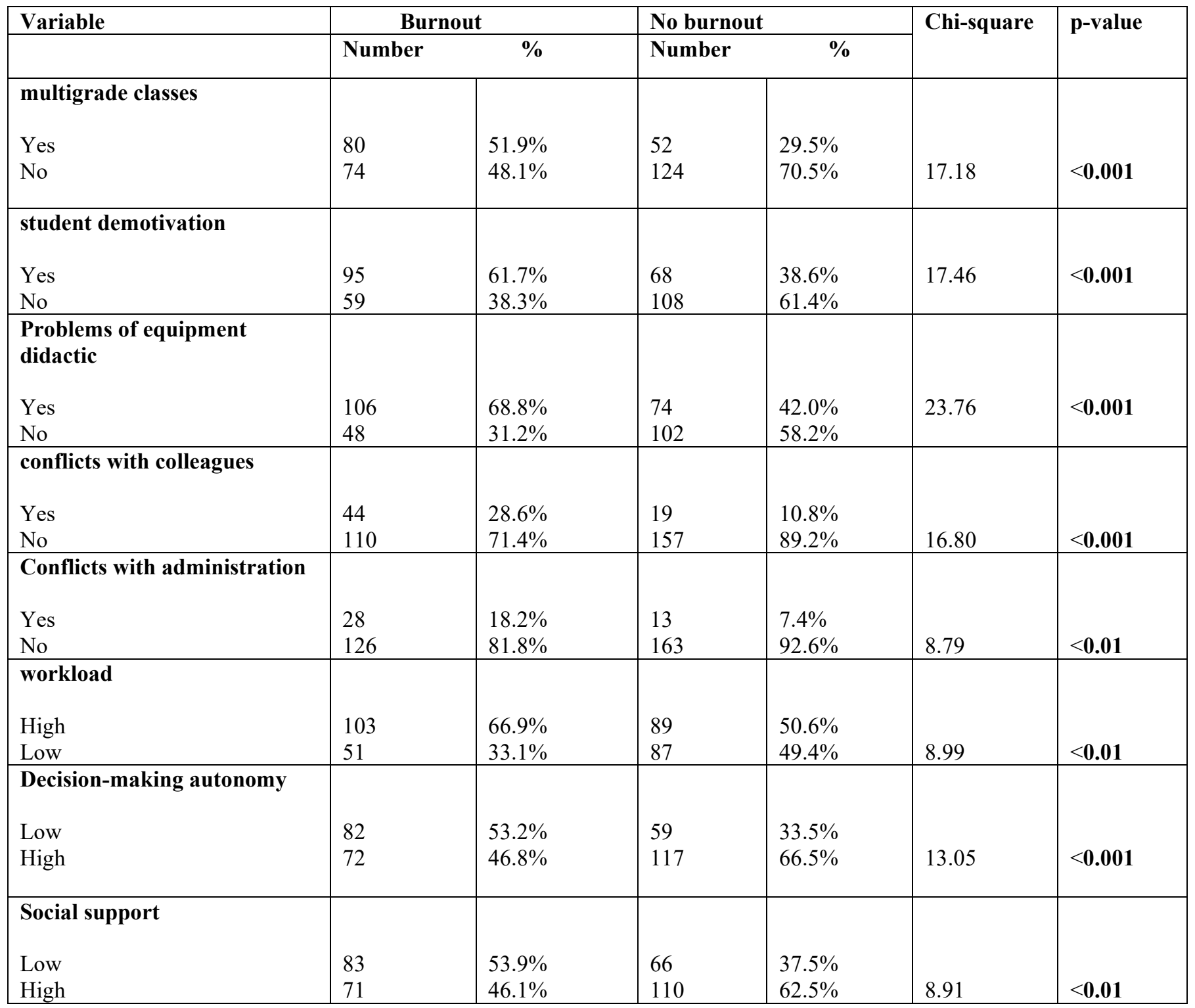

Table 5: Logistic regression analysis of independent predictors of burnout among primary school teachers ( $\mathrm{n}=330$ ) in Wazzane, 2017/2018

\begin{tabular}{|c|c|c|c|c|c|}
\hline Variable & B & p-value & OR & \multicolumn{2}{|c|}{ 95\%CI } \\
\hline Sex (female) & $-0,743$ & 0,004 & 0,476 & 0,286 & 3,791 \\
\hline $\begin{array}{c}\text { Problems of equipment } \\
\text { didactic }\end{array}$ & 0,774 & 0,003 & 2,169 & 1,302 & 3,615 \\
\hline Student demotivation & $-0,59$ & 0,032 & 0,554 & 0,324 & 0,95 \\
\hline
\end{tabular}


A. Amri et al. / Advances in Science, Technology and Engineering Systems Journal Vol. 5, No. 6, 636-641 (2020)

\begin{tabular}{|c|c|c|c|c|c|}
\hline Conflicts with colleagues & 0,733 & 0,029 & 2,081 & 1,079 & 4,015 \\
\hline Work overload & 0,718 & 0,005 & 2,05 & 1,24 & 3,389 \\
\hline $\begin{array}{c}\text { Low decision-making } \\
\text { autonomy }\end{array}$ & $-0,787$ & 0,003 & 0,455 & 0,272 & 0,764 \\
\hline
\end{tabular}

OR: 0dds-Ratio; CI: Confidence Interval

These results show the importance of knowing certain stress factors specific to the teaching profession. Thus, problems of didactic equipment, student demotivation, work overload and low decision-making autonomy are risk factors that threaten the psychological health of the Moroccan teacher.

\section{Discussion}

The objective of our study was to evaluate burnout and determine its prevalence and risk factors among a sample of Moroccan primary school teachers.

In Morocco, no study had yet been carried out among primary school teachers. Most of the studies on burnout concerned the health care professions. However, the teacher may also be exposed to this pathology, as confirmed by many of foreign studies $[8,9,10]$. The prevalence of burnout found in our study is $46.6 \%$, which is higher than that found in the studies of some Arab countries, for example $21 \%$ in Tunisia [11], $24.5 \%$ in Iraq [12]. However, it remains lower than that found in a Moroccan study conducted among university teachers where it exceeds $60 \%$ [13] and that found in some Asian countries where it can reach 50 to $70 \%$ [5]. The difference in the prevalence of burnout between studies can be explained by variations in assessment tools and methods, socio-cultural factors, the timing of data collection and teachers' coping strategies to deal with stress. In this study, age and years of service were not associated with burnout, which is consistent with the study by Van Der Doef and Maes [14]. However, in a meta-analysis involving 5 to 35 studies and 1,092 to 10,818 subjects, the association between burnout and age, and burnout and experience was demonstrated, the older and more experienced subjects had lower burnout levels [15].

For gender, it was significantly related to burnout, and women were more exhausted than men, which is consistent with other studies that have reported that female teachers experienced burnout more than teachers [16,17], and a meta-analysis that looked at the effect of gender on burnout reported significantly higher overall burnout scores for women [18].

With regard to teacher burnout, the literature has clearly objectified the link between work-related risk factors and the development of burnout [5]. The main stressors described in the international literature include poor material conditions, work overload, organizational factors, but also administrative difficulties and role conflicts $[9,19,20]$. In our study, logistic regression revealed that the work-related risk factors that predict burnout were work overload $(\mathrm{p}<0.01)$; low decision-making autonomy $(\mathrm{p}<0.01)$; the Problems of equipment didactic $(\mathrm{p}<0,01)$; work overload $(p<0.01)$; student demotivation $(p<0.05)$ and conflicts with colleagues $(\mathrm{p}<0.05)$.

For work overload and low decision-making autonomy, the results found are consistent with a study that looked at associations between work demands (workload) and resources (autonomy, degree of control) and burnout. Positive correlations were found for work demands and negative correlations were found for perceived resources [21]. In the same vein, a metaanalysis of one hundred and seventy-nine articles, representing 186,440 topics treating the associations between burnout and perceived work demands and resources, showed that there are positive correlations with cognitive workload at work and negative correlations with the "Resources" category: autonomy, support from colleagues, knowledge, management style, and feeling of security [22]. For other work-related factors, our work revealed a significant link between burnout and the Problems of equipment didactic, which is consistent with several studies that have found that the material conditions of the school environment play a significant role in teacher distress and dissatisfaction $[8$, 23]. Addition, student demotivation also represents a risk factor for the development of burnout in this study, and the literature has widely reported the association of burnout with relationship problems with students. Thus, a study, which involved 2558 teachers in France, showed a significant association between difficulties with students and the three pathological dimensions of burnout [24].

\section{Conclusion}

The Moroccan educational context is affected by a plethora of risk factors that can affect the psychological health of teachers. It is necessary to carry out serious studies on the quality of life at work, teacher satisfaction and psychological health in order to establish a prevention program at different levels and protect this true wealth of Morocco.

\section{Conflict of Interest}

The authors declare no conflict of interest.

\section{References}

[1] H.J Freudenberger. New psychotherapy approaches with teenagers in a new world. Psychotherapy, 1971, 8(1). DOI: https://doi.org/10.1111/j.15404560.1974.tb00706.x

[2] C. Maslach, MP. Leiter, Early predictors of job burnout and engagement. J Appl Psychol, 93,498-512, 2008. DOI: 10.1037 / 0021-9010.93.3.498.

[3] Direction de l'Animation de la Recherche, des Études et des Statistiques. Les facteurs psychosociaux au travail, les indicateurs disponibles. Consulted on 21/09/2020. Available on: https://travail-emploi.gouv.fr/IMG/pdf/2014031.pdf

[4] C. J Travers, C. L Cooper. Stress in teaching. In D. Shorrocks-Taylor (Ed.), Directions in educational psychology. London: Whurr publishers, 365-390, 2018.

[5] C. Maslach, WB. Schaufeli, MP. Leiter, Job burnout. Annu Rev Psychol, 52:397-422, 2001. DOI:https://doi.org/10.1146/annurev.psych.52.1.397

[6] R. Bourbonnais, M. Comeau, M. Vézina, G. Dion. Job strain, psychological distress, and burnout in nurses. Am J Ind Med. Jul; 34(1):20-8. 1998. DOI:10.1002/(sici)10970274(199807)

[7] C. Maslach, S.E Jackson. The measurement of experienced burnout. Journal 
of Occupational Behavior,2,99-113,1981. DOI:https://doi.org/10.1002/job.403002020

[8] G. Jaoul, V. Kovess. FSP-MGEN. Le burnout dans la profession enseignante. Ann Medpsychol, 162(1):26-35,2004.

[9] PJ. Mazur, MD. Lynch, Differential impact of administrative, organizational and personality factors on teacher burnout. Teach Teach Educ, 5(4):337-53, 1989.

[10] V. Tsenova, T. Tat'ozov, TS. Antonova, et al. The prevalence of the burnout syndrome in the personnel of children's institutions. Probl Khig, 20:90100,1995 .

[11] L. Channoufi, F. Ellouze, W. Cherif, M. Mersni, M.F, M'rad. Stress et épuisement professionnel des enseignants tunisiens. L'Encéphale, 38, 480487,2012.DOI: 10.1016/J.ENCEP.2011.12.012

[12] J. Al-Asadi, S. Shukrya Khalaf, A. Al-Waaly, A. Abed, S. Shami. Burnout among primary school teachers in Iraq: prevalence and risk factors EMHJ, 24, 3, 2018. Consulted on 21/09/2020. Availableon :https://applications.emro.who.int/emhj/v24/03/EMHJ_2018_2 $4 \quad 3 \quad 262$ 268.pdf?ua $=1 \& u a=1$

[13] M.S., Elmossati, A.O.T. Ahami, H. Oudda, Y. Elkettani. Évaluation de l'épuisement professionnel chez les enseignants universitaires au Maroc. International Journal of Innovation and Applied Studies. IJIAS, 16, 914-921, 2016.

[14] M. Van der Doef, S. Maes. Teacher-specific quality of work versus general quality of work assessment: A comparison of their validity regarding burnout, psychosomatic well-being and job satisfaction. Anxiety, Stress and Coping. 15, 327-344, 2002.

[15] EW. Brewer, L. Shapard. Employee burnout: A meta-analysis of the relationship between age or years of experience. Human Resource Development Review, 3(2),102-23,2004. DOI: https://doi.org/10.1177/1534484304263335

[16] PSY Lau, MT Yuen, RMC Chan. Do demographic characteristics make a difference to burnout among Hong Kong secondary school teachers? Soc
Indic Res, 71, 491-516, 2005. DOI: https://doi.org/10.1007/s11205-0048033-z.

[17] L. Zhang, J. Zhao, H. Xiao, H. Zheng, Y. Xiao, M. Chen, et al. Mental health and burnout in primary and secondary school teachers in the remote mountain areas of Guangdong Province in the People's Republic of China. Neuropsychiatr Dis Treat, 10:123-30; 2014. DOI: 10.2147 / NDT.S56020.

[18] RK. Purvanova, JP. Muros. Gender differences in burnout: A meta-analysis. Journal of Vocational Behavior, 77(2) :168-85;2010. DOI: 10.1016/j.jvb.2010.04.006

[19]. Genoud PA, Brodard F, Reicherts M. Facteurs de stress et burnout chez les enseignants de l'école primaire. Rev Eur Psychol Appl, 59(1):37-45;2009. DOI:10.1016/j.erap.2007.03.001 A

[20]. Rudow B. Stress and Burnout among teaching profession: european studies, issues and research perspectives. In: Vandenberghe R, Huberman AM, editors. Understanding and preventing teacher burnout: a sourcebook of international research and practice. Cambridge: Cambridge University Press; 38-58,1999. DOI:10.1017/CBO9780511527784.004

[21] GM. Alarcon. A meta-analysis of burnout with job demands, resources, and attitudes. Journal of Vocational Behavior, 79(2):549-62, 2011. DOI: 10.1016/j.jvb.2011.03.007

[22]. Nahrgang JD, Morgeson FP, Hofmann DA. Safety at work: a meta-analytic investigation of the link between job demands, job resources, burnout, engagement, and safety outcomes. The Journal of applied psychology, 96(1):71- 94, 2011. DOI: 10.1037 / a0021484.

[23] A. Khebbeb. Stress et satisfaction au travail dans le métier d'enseignant universitaire. Rev Sci Hum, 25:5-18,2006.

[24] MN. Vercambre, P. Brosselin, F. Gilbert, et al. Individual and contextual covariates of burnout: a cross-sectional nationwide study of French teachers. BMC Public Health, 9(333):1-12, 2009. DOI: 10.1186 / 1471-2458-9-333. 